\title{
Activin A induces apoptosis of mouse myeloma cells via the mitochondrial pathway
}

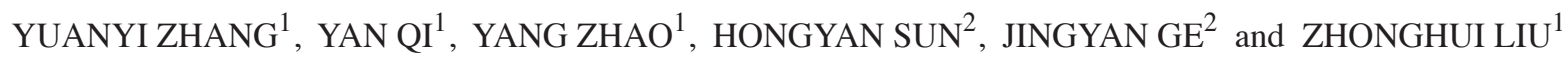 \\ Departments of ${ }^{1}$ Immunology and ${ }^{2}$ Physiology, College of Basic Medical Sciences, \\ Jilin University, Changchun, Jilin 130021, P.R. China
}

Received February 12, 2017; Accepted November 2, 2017

DOI: $10.3892 / \mathrm{ol} .2017 .7584$

\begin{abstract}
Activin A is a pleiotropic cytokine belonging to the transforming growth factor $\beta$ superfamily. Abnormal expression of activin $\mathrm{A}$ is associated with tumorigenesis. Multiple myeloma is characterized by the development of osteolytic disease, which ultimately leads to cachexia. However, the involvement of activin A in myeloma cell viability and apoptosis remains to be fully elucidated. For this purpose, mouse myeloma NS-1 cells were treated with activin A, and subsequently subjected to 5-bromo-2'-deoxyuridine analysis, Hoechst 33342 staining, flow cytometry and western blot analysis. The results revealed that activin A significantly suppressed NS-1 cell viability, and induced NS-1 cell apoptosis. In addition, activin A-induced promotion of NS-1 cell apoptosis was accompanied by upregulated expression of BCL2 associated X, apoptosis regulator (Bax), but downregulated expression of $\mathrm{B}$ cell lymphoma-2 $(\mathrm{Bcl}-2)$, resulting in an increase of the $\mathrm{Bax} / \mathrm{Bcl}-2$ ratio. Furthermore, cytochrome $c$ and caspase-3 protein expression also increased following treatment with activin $\mathrm{A}$. These data suggest that activin $\mathrm{A}$ induces apoptosis in mouse myeloma NS-1 cells via the mitochondrial pathway, providing a novel insight into multiple myeloma treatment.
\end{abstract}

\section{Introduction}

Activin $\mathrm{A}$, a homodimer of two inhibin $\beta \mathrm{A}$ subunits linked by disulphide, belongs to the transforming growth factor $\beta$ (TGF- $\beta$ ) superfamily. It was initially isolated from porcine

Correspondence to: Dr Zhonghui Liu, Department of Immunology, College of Basic Medical Sciences, Jilin University, 126 Xinmin Street, Changchun, Jilin 130021, P.R. China

E-mail: liuzh@jlu.edu.cn

Ms. Jingyan Ge, Department of Physiology, College of Basic Medical Sciences, Jilin University, 126 Xinmin Street, Changchun, Jilin 130021, P.R. China

E-mail: gejy@jlu.edu.cn

Key words: myeloma cells, activin A, apoptosis, mitochondrial pathway follicular fluid and is also known as follicle-stimulating hormone $(\mathrm{FSH})$ releasing protein, due to its capacity to induce the release of FSH from the pituitary gland (1). Subsequent research has demonstrated that activin $\mathrm{A}$ is involved in pleiotropic functions including inflammation, arterial pressure regulation, embryonic development and tumourigenesis (2-5). As with other TGF- $\beta$ superfamily members, activin A functions through the serine/threonine kinase pathway. Activin A initially binds to activin type II receptors (ActRII), and then recruits activin type I receptors to phosphorylate and activate SMAD family member (Smad) $2 / 3$ in the cytoplasm, with this being the common signaling molecule between activin and TGF- $\beta$ (6). The activated Smad $2 / 3$ forms a complex with Smad4 and then the complex is translocated into the nucleus, resulting in downstream target gene transcription to elicit biological effects, including cell differentiation, proliferation and apoptosis $(7,8)$.

Activin A is known to modulate multiple types of cancer. It not only promotes the genesis and progression of certain tumors, but also inhibits tumorigenesis in other instances, depending on the cell types involved and other interacting pathways (6). For example, activin A suppresses the proliferation of breast cancer cells and pituitary adenoma cells, while promoting the proliferation of ovarian carcinoma cells. Myeloma cells induce bone marrow stromal cells to secrete activin A, which in turn inhibits osteogenesis and induces osteolysis and cachexia (9). However, the effects of activin A on myeloma cell viability and apoptosis remain unclear. Therefore, in the present study, the effects of activin A on viability and apoptosis in the mouse myeloma cell line NS-1 were investigated, and the mechanisms underlying activin A action were analyzed by examining the expression of apoptosis-associated proteins.

\section{Materials and methods}

Reagents. Activin A (cat. no. 338-AC) and allophoycocyanin-labeled ActRIIA antibodies (cat. no. FAB340A) were obtained from R\&D Systems, Inc. (Minneapolis, MN, USA). RPMI-1640 culture medium was bought from Gibco; Thermo Fisher Scientfic, Inc. (Waltham, MA, USA). The Reverse transcription-polymerase chain reaction (RT-PCR) kit was provided by Takara Biotechnology Co., Ltd. (Dalian, China). Protein extraction kits were bought from Thermo Fisher Scientific, Inc. GAPDH antibodies (cat. no. KM9002) were 
purchased from Tianjin Sungene Biotech Co., Ltd. (Tianjin, China). The 5-bromo-2'-deoxyuridine (BrdU) cell proliferation kit and fluorescein isothiocyanate (FITC)-Annexin V apoptosis kit were obtained from Roche Diagnostics (Indianapolis, IN, USA). B cell lymphoma-2 (Bcl-2) (cat. no. 554218) antibodies were bought from BD Biosciences (Franklin Lakes, NJ, USA). Cleaved caspase-3 antibodies (cat. no. 9661), BCL2 associated $\mathrm{X}$, apoptosis regulator (Bax) (cat. no. 3498) and cytochrome $c$ (Cyt $c$ ) antibodies (cat. no. 2772) were purchased from Cell Signaling Technology, Inc. (Danvers, MA, USA). Goat anti-rabbit immunoglobulin (Ig) G-Peroxidase antibodies (cat. no. A0545) and anti-mouse IgG-Peroxidase antibodies (cat. no. A3682) were purchased from Sigma-Aldrich (Merck KGaA, Darmstadt, Germany). ECL-Plus (cat. no. RPN2232) was supplied by GE Healthcare Life Sciences (Little Chalfont, UK).

Cell culture. The mouse myeloma NS-1 cell line was provided by the American Type Culture Collection (Manasass, VA, USA) and cultured in RPMI-1640 medium with $10 \%$ fetal bovine serum (cat. no. 04-001-1ACS; Biological Industries, Kibbutz Beit-Haemek, Israel) in a 5\% $\mathrm{CO}_{2}$-humidified atmosphere at $37^{\circ} \mathrm{C}$.

$R T$-PCR. Total RNA from NS-1 cells was extracted using TRIzol reagent (Invitrogen; Thermo Fisher Scientific, Inc.) in accordance with the manufacturer's protocol). cDNA synthesis was performed using a PrimeScript ${ }^{\circledR} 1$ st Strand cDNA Synthesis kit (Takara Biotechnology Co., Ltd.) and the cDNA was amplified using Premix Taq ${ }^{\mathrm{TM}}$ (cat. no. R004A; Takara Biotechnology Co., Ltd.) with target gene-specific primers according to the manufacturers protocol. PCR was performed using the following reaction conditions: $94^{\circ} \mathrm{C}$ for $30 \mathrm{sec}\left(35\right.$ cycles), $55^{\circ} \mathrm{C}$ for $20 \mathrm{sec}\left(35\right.$ cycles), $72^{\circ} \mathrm{C}$ for $40 \mathrm{sec}(35 \mathrm{cycles})$ and final extension was $72^{\circ} \mathrm{C}$ for $10 \mathrm{~min}$. The primers were as follows: ActRIIA forward, 5'-ATTGGC CAGCATCCATCTCTTG-3' and reverse, 5'-GCCACCATC ATAGACTAGATTC-3'; ActRIIB forward, 5'-TGCTGAAGA GCGACCTCAC-3' and reverse, 5'-AGCAGGTCCACATTG GTGAC-3'; GAPDH forward, 5'-GATTGTTGCCATCAA CGACC-3' and reverse, 5'-GTGCAGGATGCATTGCTG AC-3'. GAPDH was used as a positive internal reference, and adding no cDNA to the PCR reaction system was regarded as a negative control. PCR products were subjected to $2 \%$ agarose gel electrophoresis with ethidium bromide at room temperature for $1 \mathrm{~h}$. The specific bands were visualized using an ImageMaster VDS system (GE Healthcare Life Sciences, Little Chalfont, UK). Densitometric quantification of mRNA was normalized to the internal control GAPDH.

BrdU cell viability assay. NS- 1 cells $\left(2 \times 10^{4}\right.$ cells/well $)$ were seeded into 96-well culture plates in RPMI 1640 medium with 5\% fetal bovine serum (cat. no. 04-001-1ACS; Biological Industries, Kibbutz Beit-Haemek, Israel) in $5 \% \mathrm{CO}_{2}$ at $37^{\circ} \mathrm{C}$. The cells were then treated with $0-20 \mathrm{ng} / \mathrm{ml}$ of activin A $(2 \mu \mathrm{g} / \mathrm{ml})$ for $24 \mathrm{~h}$, followed by incubation with $10 \mu \mathrm{mol} / 1 \mathrm{BrdU}$ at $37^{\circ} \mathrm{C}$ for $2 \mathrm{~h}$. The supernatant was discarded, and $100 \mu \mathrm{l}$ FixDenat per well was added and incubated for a further $30 \mathrm{~min}$ at room temperature. The supernatant was removed, $100 \mu 1$ anti-BrdU-peroxidase working solution was added, and cells were incubated at $37^{\circ} \mathrm{C}$ in the dark for $90 \mathrm{~min}$. The cells were washed three times with PBS and substrate solution (100 $\mu \mathrm{l}$ per well) was added at room temperature for $10 \mathrm{~min}$. Finally, $1 \mathrm{~mol} / 1 \mathrm{H}_{2} \mathrm{SO}_{4} 25 \mu \mathrm{l}$ was added, and the absorbance at $450 \mathrm{~nm}$ was detected to evaluate cell viability.

Hoechst 33342 staining. NS-1 cells $\left(2 \times 10^{4}\right.$ cells/well) were seeded into 96-well culture plates in RPMI 1640 medium with $5 \%$ fetal bovine serum, and treated with $10 \mathrm{ng} / \mathrm{ml}$ activin A for $24 \mathrm{~h}$ at $37^{\circ} \mathrm{C}$. The cells were washed three times with PBS and incubated with $50 \mu \mathrm{l}$ Hoechst $33342(100 \mu \mathrm{g} / \mathrm{ml})$ at room temperature for $10 \mathrm{~min}$. The cells were washed twice in PBS, and then cell morphology was observed under a fluorescence microscope (IX71) and photographed with a microscope digital camera system (Olympus Corporation, Tokyo, Japan).

Flow cytometry for cells apoptosis assay. NS-1 cells $\left(1 \times 10^{6}\right.$ cells/well) were seeded in 12-well culture plates in RPMI 1640 medium with 5\% fetal bovine serum. Following treatment with $10 \mathrm{ng} / \mathrm{ml}$ of activin A at $37^{\circ} \mathrm{C}$ for $24 \mathrm{~h}$, NS-1 cells were collected and re-suspended in $100 \mu$ l fluorescence-activated cell sorting buffer, followed by the addition of $1 \mu 1$ FITC-Annexin V and $1 \mu 1$ 7-aminoactinomycin (7-AAD) at room temperature for $5 \mathrm{~min}$ in the dark. Then, the labeled cells were analyzed using flow cytometry (BD Calibur; BD Biosciences). Data were collected and analyzed with Cell Quest software (version 7.6; BD Biosciences) to obtain the percentage of fluorescence cells.

Western blotting. NS-1 cells $\left(1 \times 10^{6}\right.$ cells/well) were seeded into 12-well culture plates in RPMI 1640 medium with 5\% fetal bovine serum. Following treatment with activin $\mathrm{A}$ at $37^{\circ} \mathrm{C}$ for $12 \mathrm{~h}$, cells were resuspended with PBS and harvested using centrifugation at $850 \mathrm{xg}$ for $10 \mathrm{~min}$ at $4^{\circ} \mathrm{C}$, then lysed in protein lysis buffer (1\% Nonidet P-40, 50 mmol/l Tris- $\mathrm{HCl}(\mathrm{pH} 7.5)$, $150 \mathrm{mmol} / \mathrm{l} \mathrm{NaCl}, 1 \mathrm{mmol} / \mathrm{l} \mathrm{NaF}, 1 \mathrm{mmol} / 1$ phenylmethylsulfonyl fluoride, $4 \mu \mathrm{g} / \mathrm{ml}$ leupeptin and $1 \mu \mathrm{g} / \mathrm{ml}$ aprotinin) at $37^{\circ} \mathrm{C}$ for $15 \mathrm{~min}$, followed by vortex at room temperature for $15 \mathrm{~min}$. The lysate was removed using centrifugation at $15,000 \mathrm{xg}$ for $10 \mathrm{~min}$ at $4^{\circ} \mathrm{C}$, and protein $(30 \mu \mathrm{g})$ were separated by SDS-PAGE (12\% gel) and transferred onto a polyvinylidene difluoride membrane. Then, the membrane was blocked with 2\% BSA (cat. no. B2064; Sigma-Aldrichl; Merck KGaA) for $1 \mathrm{~h}$ at room temperature and probed with mouse $\mathrm{Bcl}-2$ antibodies (1:1,000 dilution), rabbit Bax antibodies (1:500 dilution), rabbit cleaved capase-3 antibodies (1:500 dilution), rabbit Cyt $c$ antibodies (1:500 dilution) and mouse GAPDH antibodies $(1: 1,000)$ at $4^{\circ} \mathrm{C}$ overnight. Following washing with $1 \mathrm{x}$ TBST with $0.1 \%$ Tween-20 three times, the membranes were incubated with horseradish peroxidase-conjugated goat anti-rabbit IgG antibodies (1:160,000; cat. no. A0545; Sigma-Aldrich; Merck KGaA) or anti-mouse IgG antibodies (1:160,000; cat. no. A3682; Sigma-Aldrich; Merck KGaA) for $1 \mathrm{~h}$ at room temperature. Labeled proteins were detected using enhanced chemiluminescence reagents within the ECL-Plus with ImageQuant LAS 4010 kit (GE Healthcare Life Sciences) and analyzed using ImageJ software (v1.43, NIH USA). Protein levels were normalized to the internal control GAPDH.

Statistical analysis. Experiments were repeated at least three times. All data were presented as the mean \pm standard 

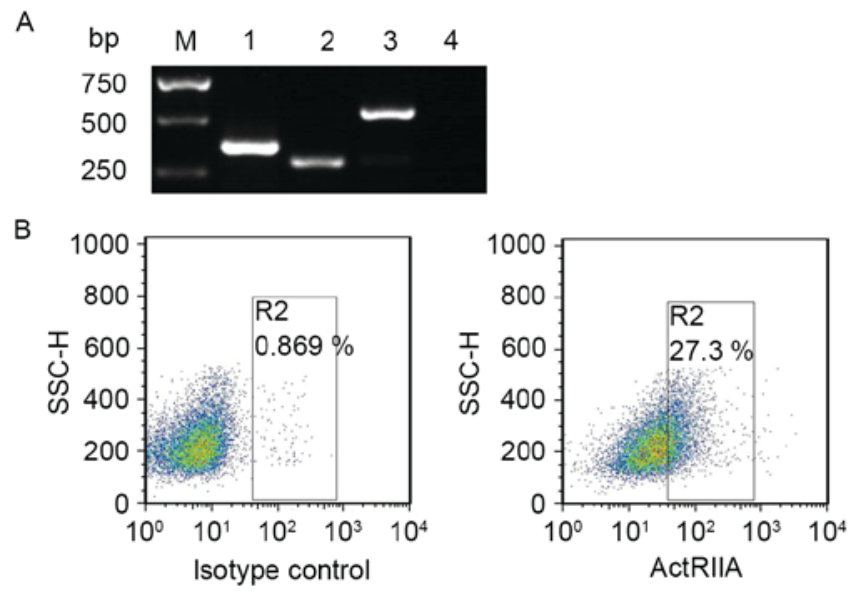

Figure 1. Expression of ActRII in NS-1 cells. (A) Expression of ActRIIA and ActRIIB mRNA in NS-1 cells was examined by reverse transcription polymerase chain reaction. Lane 1, GAPDH (371 bp); lane 2, ActRIIB (544 bp); lane 3, ActRIIA (296 bp). (B) Expression of ActRIIA protein on NS-1 cells was detected by flow cytometry with allophycocyanin-labeled ActRIIA antibodies and normal immunoglobulin $\mathrm{G}$ as an isotype control, respectively. ActRII, activin type II receptor; M, molecular weight (bp).

deviation. Statistical comparisons were performed using one-way analysis of variance, followed by the Scheffe's test. The statistical differences between two groups were determined using Student's t-test. $\mathrm{P}<0.05$ was considered to indicate a statistically significant difference.

\section{Results}

Expression of ActRIIA in NS-1 cells. Activin A initially binds to ActRIIA or ActRIIB, and then activates downstream signaling molecules (10). To confirm whether activin A exerted an effect on NS-1 cells, ActRII mRNA expression was initially examined in NS-1 cells. The results of RT-PCR revealed that ActRIIA and ActRIIB mRNA expression were detectable in NS-1 cells (Fig. 1A). Furthermore, flow cytometry results also demonstrated that ActRIIA protein was expressed on NS-1 cells (Fig. 1B). These data suggested that activin A exerted an effect on NS-1 cells via binding ActRII.

Inhibitory effects of activin A on NS-1 cell viability. In order to evaluate the biological functions of activin A, NS-1 cell viability was examined by BrdU assay. The results revealed that following treatment with activin A for $24 \mathrm{~h}$, NS-1 cell viability was inhibited in a dose-dependent manner, compared with the untreated control group (Fig. 2).

NS-1 cell apoptosis was induced by activin A. In order to assess the effect of activin A on NS-1 cell apoptosis, NS-1 cellular morphology was first examined by Hoechst 33342 staining following treatment with activin A for $24 \mathrm{~h}$. In the control group, the cells were uniform in size and round in shape. However, the morphology of cells treated with activin A was notably different in terms of size and shape, and the number of cells with nuclear condensation was visibly increased (Fig. 3A). Furthermore, the flow cytometry results revealed that, following treatment with activin A for $24 \mathrm{~h}$, the ratio of apoptotic NS-1 cells significantly increased compared
A

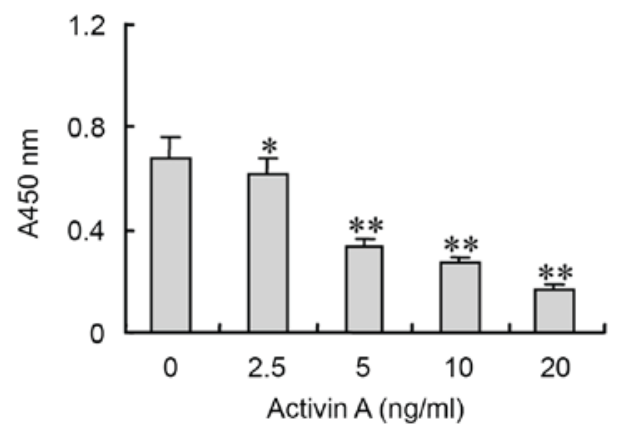

B

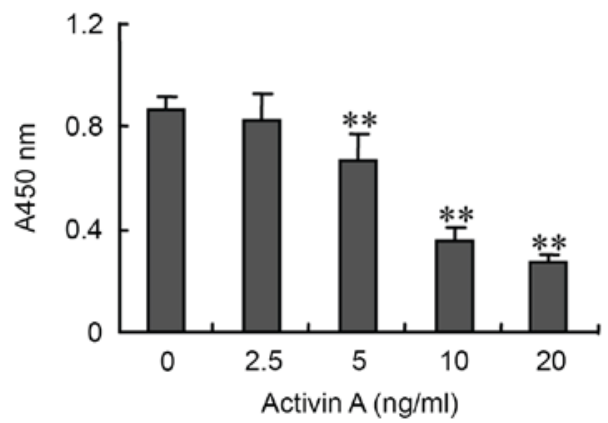

Figure 2. Effect of activin A on NS-1 cell viability. NS-1 cells were plated at a density of (A) $1 \times 10^{4}$ cells/well and (B) $2 \times 10^{4}$ cells/well were treated with $0-20 \mathrm{ng} / \mathrm{ml}$ of activin A for $24 \mathrm{~h}$, followed by incubation with $10 \mu \mathrm{mol} / 1$ 5-bromo-2'-deoxyuridine for $2 \mathrm{~h}$. The A450 $\mathrm{nm}$ was detected to evaluate the cell viability. ${ }^{*} \mathrm{P}<0.05$ and ${ }^{* *} \mathrm{P}<0.01$ vs. $0 \mathrm{ng} / \mathrm{ml}$ control group. A450, absorbance at $450 \mathrm{~nm}$.

with the control group (Fig. 3B). These data indicated that activin A induced NS-1 cell apoptosis.

Expression levels of apoptosis-associated proteins in NS-1 cells treated with activin $A$. Previous studies have revealed that activin A induces B cell apoptosis through the mitochondrial apoptosis pathway (11). In the present study, the expression levels of the apoptosis-associated proteins Bcl-2, Bax, Cyt $c$ and caspase- 3 were examined by western blotting. The results revealed that activin A significantly upregulated Bax protein expression, while $5.0 \mathrm{ng} / \mathrm{ml}$ activin A treatment downregulated $\mathrm{Bcl}-2$ protein expression, which resulted in an increased ratio of Bax/Bcl-2 (Fig. 4). Activin A also increased the expression of Cyt $c$ (at 2.5 and $5.0 \mathrm{ng} / \mathrm{ml}$ ) and cleaved caspase-3 proteins (at $5.0 \mathrm{ng} / \mathrm{ml}$; Fig. 4). These data suggested that activin A may induce NS-1 cell apoptosis through the mitochondrial apoptosis pathway.

\section{Discussion}

Activin A is a multifunctional factor of TGF- $\beta$ superfamily that is most commonly involved in embryogenesis and gonadal hormone release $(12,13)$. Activin A is also associated with the maintenance of neuron survival, induction of hepatocyte apoptosis, promotion of erythroid differentiation and dual regulation of macrophage activation (14-17). The involvement of activin $\mathrm{A}$ in the process of tumor genesis and progression has been previously reported (18), and a significant increase of activin A in the serum of certain patients with colorectal adenocarcinoma has been observed (19). However, 


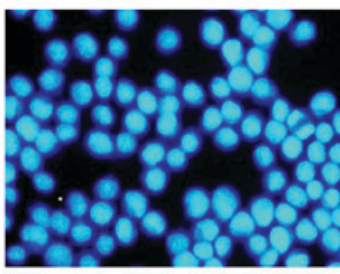

Control

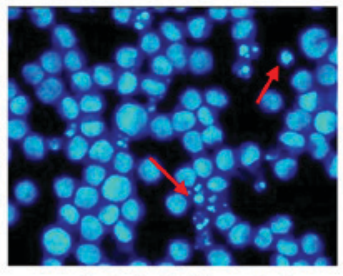

Activin A $(10 \mathrm{ng} / \mathrm{ml})$

B
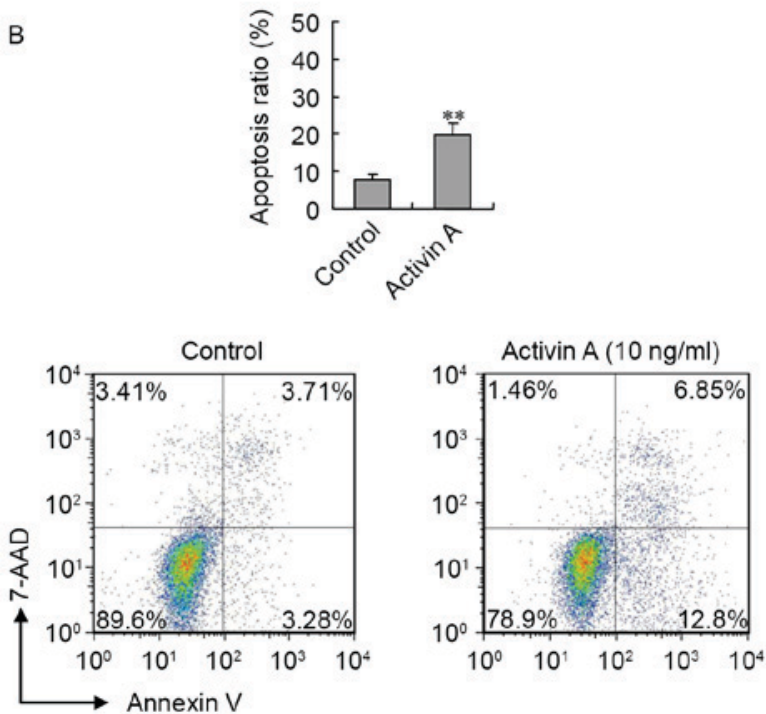

Figure 3. Apoptosis assay of NS-1 cells treated with activin A. NS-1 cells were incubated in the absence of activin A (control) or presence of $10 \mathrm{ng} / \mathrm{ml}$ activin A (activin A) for $24 \mathrm{~h}$. (A) The morphology of NS-1 cells was examined by Hoechst 33342 staining (magnification, x100). Arrows represen the apoptotic cells. (B) NS-1 cells were stained with fluorescein isothiocyanate-Annexin V/7-AAD, and then the percentage of fluorescence cells was analyzed by flow cytometry. The graph represents the mean \pm standard deviation of triplicate determinations. ${ }^{* *} \mathrm{P}<0.01$ vs. control group. 7-AAD, 7-aminoactinomycin.

the function of activin $\mathrm{A}$ in tumor progression is controversial. Activin A has been demonstrated to exert a primarily protective function, whereby it induces cell cycle arrest of patient-derived prostate cancer cells and non-invasive prostate cancer LNCaP cells. In contrast, activin A treatment resulted in an increase in proliferation of the more aggressive prostate cancer cell line, PC3, an apparent discrepancy (20-22). The tumor suppressive function of activin $\mathrm{A}$ is also observed in breast cancer, but activing A promotes cell proliferation and invasion in head and neck squamous cell carcinoma, resulting in a poor prognosis (8). Multiple myeloma is characterized by the development of osteolytic disease. Circulating activin A is elevated in patients with advanced multiple myeloma, which contributes to bone remodeling. Malignant plasma cells have been reported to induce the secretion of activin A by stromal cells, resulting in osteoblast inhibition and osteoclast stimulation in vitro and in vivo $(9,23,24)$. Although activin A seems to be implicated into the pathogenesis of myeloma bone disease, the direct effect of activin A on myeloma cell viability and apoptosis remains unclear.

Activin A is a dimeric, multifunctional cytokine, which is involved in a broad spectrum of functions associated with cell viability and apoptosis, and is also associated with tumor genesis and progression, aggressiveness and malignant
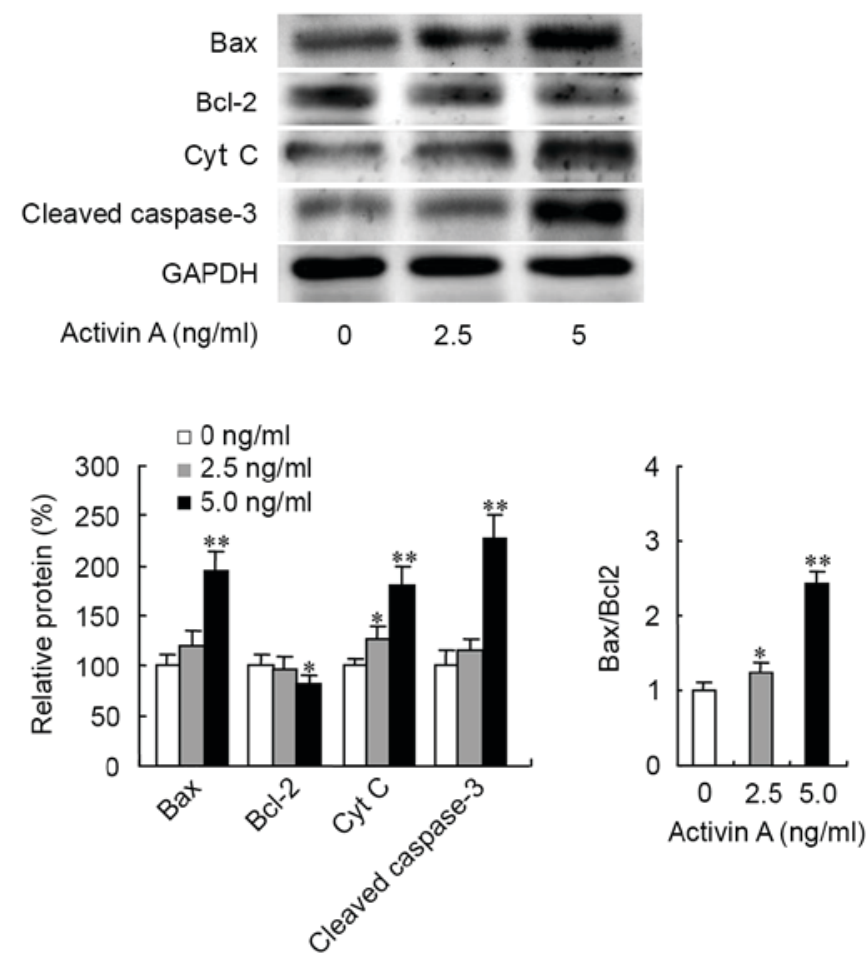

Figure 4. Expression of the apoptosis-associated proteins Bax, Bcl-2, Cyt c and cleaved caspase-3 in NS-1 cells treated with $0-5 \mathrm{ng} / \mathrm{ml}$ of activin A for $12 \mathrm{~h}$, as assessed by western blotting. The graph represents relative protein expression levels from triplicate determinations, and the protein levels of the control group were adjusted to $100 \%$. ${ }^{*} \mathrm{P}<0.05$ and ${ }^{* *} \mathrm{P}<0.01$ vs. control group. Bax, BCL2 associated X, apoptosis regulator; Bcl-2, B cell lymphoma 2; Cyt c, cytochrome $c$.

degree $(3,4,19)$. In the present study, the effects of activin A on myeloma NS-1 cell viability and apoptosis were evaluated. Our data revealed that ActRIIA and ActRIIB were expressed in NS-1 cells, indicating that activin A exerts an effect on NS-1 cells. Moreover, the results showed that activin A significantly inhibited the viability of NS-1 cells in a dose-dependent manner. Hoechst 33342 staining revealed that the size of NS-1 cells was altered compared with controls, and the shape appeared irregular following treatment with activin A. In addition, the number of cells with nuclear condensation visibly increased. Furthermore, the results of flow cytometry and staining with AnnexinV-7-AAD revealed that the ratio of apoptotic NS-1 cells increased following administration of activin A, compared with untreated NS-1 cells. These data indicated that activin A inhibited NS-1 cell viability and induced apoptosis in NS-1 cells.

Apoptosis is recognized as a form of programmed cell death, characterized by nuclear fragmentation and the presence of apoptotic bodies. It is regulated by multiple genes, and serves an important function in the development and growth of normal adult tissues and the maintenance of homeostasis (25). Signal transduction pathways associated with apoptosis include the mitochondrial pathway, death receptor pathway, and endoplasmic reticulum stress pathway, of which the mitochondrial pathway serves a vital function in apoptosis $(26,27)$. The $\mathrm{Bax} / \mathrm{Bcl}-2$ ratio is the key factor that triggers the mitochondrial pathway of apoptosis, and when the ratio of $\mathrm{Bax} / \mathrm{Bcl}-2$ increases apoptosis is initiated (27-30). Bcl-2 and 
Bax proteins are located upstream of the mitochondrial apoptosis pathway and regulate the release of Cyt $c$, which is an important component of the mitochondrial electron transport chain. The release of Cyt $c$ from the mitochondria is a key step in the induction of proteases downstream from caspase-3, to regulate cell survival or death. Previous studies have demonstrated that activin A induces B cell apoptosis through the mitochondrial pathway (11), thus the effect of activin A on apoptosis-associated proteins of the mitochondrial pathway was evaluated in the present study. The results revealed that activin A significantly upregulated Bax protein expression, which resulted in an increase in the $\mathrm{Bax} / \mathrm{Bcl}-2$ ratio. Activin $\mathrm{A}$ also increased the cleaved capase- 3 and Cyt $c$ protein expression. These data suggest that activin A induces NS-1 cell apoptosis via the mitochondrial pathway.

In summary, activin A serves an important function in mouse myeloma NS-1 cell viability and apoptosis through the mitochondrial pathway, providing a potential future target for myeloma therapy.

\section{Acknowledgements}

The present study was supported by the Project of Science and Technology of Jilin Province (grant no. 20140311091YY).

\section{References}

1. Woodruff TK, Besecke LM, Groome N, Draper LB, Schwartz NB and Weiss $\mathrm{J}$ : Inhibin A and inhibin B are inversely correlated to follicle stimulating hormone, yet are discordant during the follicular phase of the rat estrous cycle and inhibin $\mathrm{A}$ is expressed in a sexually dimorphic manner. Endocrinology 137: 5463-5467, 1996.

2. Ge J, Fan Y, Lu Y, Qi Y, Wang M and Liu Z: Activin A increases arterial pressure in the hypothalamic paraventricular nucleus in rats by angiotension II. Neuroreport 27: 683-688, 2016.

3. Matzuk MM, Kumar TR, Vassalli A, Bickenbach JR, Roop DR, Jaenisch R and Bradley A: Functional analysis of activins during mammalian development. Nature 374: 354-356, 1995.

4. Hoda MA, Rozsas A, Lang E, Klikovits T, Lohinai Z, Torok S, Berta J, Bendek M, Berger W, Hegedus B, et al: High circulating activin A level is associated with tumor progression and predicts poor prognosis in lung adenocarcinoma. Oncotarget 7 : 13388-13399, 2016.

5. Antsiferova M, Martin C, Huber M, Feyerabend TB, Förster A, Hartmann K, Rodewald HR, Hohl D and Werner S: Mast cells are dispensable for normal and activin-promoted wound healing and skin carcinogenesis. J Immunol 191: 6147-6155, 2013.

6. Loomans HA and Andl CD: Intertwining of activin A and TGF $\beta$ signaling: Dual roles in cancer progression and cancer cell invasion. Cancers (Basel) 7: 70-91, 2014.

7. Niu L, Cui X, Qi Y, Xie D, Wu Q, Chen X, Ge J and Liu Z: Involvement of TGF- $\beta 1 / \mathrm{Smad} 3$ signaling in carbon Tetrachloride-induced acute liver injury in mice. PLoS One 11: e0156090, 2016.

8. Miyazawa K, Shinozaki M, Hara T, Furuya T and Miyazono K: Two major Smad pathways in TGF-beta superfamily signaling. Genes Cells 7: 1191-1204, 2002.

9. Vallet S, Mukherjee S, Vaghela N, Hideshima T, Fulciniti M, Pozzi S, Santo L, Cirstea D, Patel K, Sohani AR, et al: Activin A promotes multiple myeloma-induced osteolysis and is a promising target for myeloma bone disease. Proc Natl Acad Sci USA 107: 5124-5129, 2010.

10. Liu HY, Wang YN, Ge JY, Li N, Cui XL and Liu ZH: Localization and role of activin receptor-interacting protein 1 in mouse brain. J Neuroendocrinol 25: 87-95, 2013.
11. Yamakawa N, Tsuchida $\mathrm{K}$ and Sugino $\mathrm{H}$ : The rasGAP-binding protein, Dok-1, mediates activin signaling via serine/threonine kinase receptors. EMBO J 21: 1684-9164, 2002.

12. Duggal G, Heindryckx B, Warrier S, Taelman J, Van der Jeught M, Deforce D, Chuva de Sousa Lopes S and De Sutter P: Exogenous supplementation of Activin A enhances germ cell differentiation of human embryonic stem cells. Mol Hum Reprod 21: 410-423, 2015.

13. Okuma Y, Saito K, O'Connor AE, Phillips DJ, de Kretser DM and Hedger MP: Reciprocal regulation of activin A and inhibin B by interleukin-1 (IL-1) and follicle-stimulating hormone (FSH) in rat Sertoli cells in vitro. J Endocrinol 185: 99-110, 2005.

14. Fang L, Wang YN, Cui XL, Fang SY, Ge JY, Sun Y and Liu ZH: The role and mechanism of action of activin $\mathrm{A}$ in neurite outgrowth of chicken embryonic dorsal root ganglia. J Cell Sci 125: 1500-1507, 2012.

15. Walton KL, Makanji Y and Harrison CA: New insights into the mechanisms of activin action and inhibition. Mol Cell Endocrinol 359: 2-12, 2012.

16. Ge J, Wang Y, Feng Y, Liu H, Cui X, Chen F, Tai G and Liu Z: Direct effects of activin A on the activation of mouse macrophage RAW264.7 cells. Cell Mol Immunol 6: 129-133, 2009.

17. Li N, Cui X, Ge J, Li J, Niu L, Liu H, Qi Y, Liu Z and Wang Y. Activin A inhibits activities of lipopolysaccharide-activated macrophages via TLR4, not of TLR2 Biochem Biophys Res Commun 435: 222-228, 2013

18. Le Bras GF, Loomans HA, Taylor CJ, Revetta FL and Andl CD: Activin A balance regulates epithelial invasiveness and tumorigenesis. Lab Invest 94: 1134-1146, 2014.

19. Wu S, Qi Y, Niu LM, Xie DX, Cui XL and Liu ZH: Activin A as a novel biomarker for colorectal adenocarcinoma in humans. Eur Rev Med Pharmacol Sci 19: 4371-437, 2015.

20. Gold E and Risbridger G: Activins and activin antagonists in the prostate and prostate cancer. Mol Cell Endocrinol 359: 107-112, 2012.

21. Fujii Y, Kawakami S, Okada Y, Kageyama Y and Kihara K: Regulation of prostate-specific antigen by activin A in prostate cancer LNCaP cells. Am J Physiol Endocrinol Metab 286: E927-E931, 2004.

22. Balanathan P, Williams ED, Wang H, Pedersen JS, Horvath LG, Achen MG, Stacker SA and Risbridger GP: Elevated level of inhibin-alpha subunit is pro-tumourigenic and pro-metastatic and associated with extracapsular spread in advanced prostate cancer. Br J Cancer 100: 1784-1793, 2009.

23. Garcia-Gomez A, Sanchez-Guijo F, Del Cañizo MC, San Miguel JF and Garayoa M: Multiple myeloma mesenchymal stromal cells: Contribution to myeloma bone disease and therapeutics. World J Stem Cells 6: 322-343, 2014.

24. Terpos E, Kastritis E, Christoulas D, Gkotzamanidou M, Eleutherakis-Papaiakovou E, Kanellias N, Papatheodorou A and Dimopoulos MA: Circulating activin-A is elevated in patients with advanced multiple myeloma and correlates with extensive bone involvement and inferior survival; no alterations post-lenalidomide and dexamethasone therapy. Ann Oncol 23: 2681-2686, 2012.

25. Prokhorova EA, Zamaraev AV, Kopeina GS, Zhivotovsky B and Lavrik IN: Role of the nucleus in apoptosis: Signaling and execution. Cell Mol Life Sci 72: 4593-4612, 2015.

26. Delgado Y, Morales-Cruz M, Hernández-Román J, Martínez Y and Griebenow K: Chemical glycosylation of cytochrome c improves physical and chemical protein stability. BMC Biochem 15: 16, 2014.

27. Peng X, Yu Z, Liang N, Chi X, Li X, Jiang M, Fang J, Cui H, Lai W, Zhou Y and Zhou S: The mitochondrial and death receptor pathways involved in the thymocytes apoptosis induced by aflatoxin B1. Oncotarget 7: 12222-12234, 2016.

28. Roset R, Ortet L and Gil-Gomez G: Role of Bcl-2 family members on apoptosis: What we have learned from knock-out mice. Front Biosci 12: 4722-4730, 2007.

29. Hassan M, Watari H, AbuAlmaaty A, Ohba Y and Sakuragi N: Apoptosis and molecular targeting therapy in cancer. Biomed Res Int 2014: 150845, 2014.

30. Mignard V, Lalier L, Paris F and Vallette FM: Bioactive lipids and the control of Bax pro-apoptotic activity. Cell Death Dis 5: e1266, 2014. 